\title{
Thermolabile Isoenzyme der Glutamat-Oxalacetat-Transaminase bei Hepatitis
}

\author{
I. Mitteilung
}

\author{
Von J. Kellen und V. Romančík
}

Aus dem Zentrallaboratorium des Kreiskrankenbauses Dunajská Streda (Vorstand: Dr. med. J. Kellen, C. Sc) und der Klinik für Infektionskrankbeiten der Komenský-Universität, Bratislava, Tschechoslowakei (Vorstand: Doz. Dr. med. J. Hruizik, C. Sc.)

(Eingegangen am 16. August 1965)

\begin{abstract}
Die Glutamat-Oxalacetat-Transaminase im Serum Gesunder - im normalen Aktivitätsbereich - ist bis $58^{\circ}$ auf die Dauer von 60 Minuten weitgehend thermostabil und erleidet nur geringe Aktivitätsverlluste. Die Transaminasenaktivität im Serum Hepatitiskranker mit erhöhten Werten weist unter derselben Behandlung einen Aktivitätsverlust von $47 \pm 11 \%$ des Anfangswertes auf.
\end{abstract}

Glutamate-oxaloacetate transaminase in the serum of healthy individuals, at normal activity levels, is largely thermostable up to $58^{\circ}$ for 60 minutes with only slight loss of activity. Under the same conditions, the increased transaminase activity in the serum of hepatitic patients is decreased by $47 \pm 11 \%$.

Die Beobachtung, daß funktionell scheinbar einheitliche Enzyme mit der gleichen Substratspezifität, strukturell verschieden sein können, führte zu dem Begriff der Isoenzyme. Bald wurden solche Isoenzyme bei fast allen bekannten Enzymen nachgewiesen, und es begann die erfolgreiche Suche nach organspezifischen Eigenschaften einzelner Enzymfraktionen sowie nach Methoden zu deren Bestimmung.

Die Erfassung der Isoenzyme ist zur Zeit mit einer Reihe von Verfahren, wie der Papier- und Elutionschromatographie (auf DEAE-Cellulose (1) und DEAE-Sephadex), durch elektrophoretische Methoden (2), immunologisch und durch spezifische Inhibitoren möglich. Es ist nicht Ziel dieser Mitteilung, über die Vergleichbarkeit der mit diesen verschiedenen Methoden erhaltenen Ergebnisse zu diskutieren. Es steht jedoch fest, daß praktisch alle Verfahren mehr oder weniger unterschiedliche (oder denaturierte?) Isoenzyme erfassen, die untereinander nicht vollkommen identisch sind.

Die zum Teil beträchtlichen technischen Ansprüche, insbesondere der Säulenchromatographie, hatten Bemühungen um einfachere Aufteilungsmethoden zur Folge. Eine der neuesten machte sich mit guten Ergebnissen die unterschiedliche Thermolabilität einzelner Isoenzyme der Laktatdehydrogenase $(3,4) \mathrm{zu}$ Nutzen. In Anlehnung an diese Ergebnisse untersuchten wir in der vorliegenden Arbeit die Thermolabilität der Glutamat-Oxalacetat-Transaminase im Serum (,GOT"), wobei außer Normalsera von Blutspendern auch die typisch erhöhten Serumaktivitäten bei Kranken mit akuter Hepatitis epidemica verwendet wurden. Unseres Wissens ist bisher über thermisch inaktivierte Transaminasenfraktionen nichts bekannt.

\section{Methodik}

In frisch gewonnenem Nüchternserum wurde binnen 2 Stunden nach Blutentnahme die GOT-Aktivität nach ReItman und Frankel (5) bestimmt. Bei Aktivitäten über 140 Karmen-Einheiten - in der Regel nur bei Hepatitisserum - mußte aus methodischen Gründen das Serum mit physiologischer Kochsalzlösung im Verhältnis $1: 10$, in einigen Fällen bis $1: 20$ verdünnt werden. Alle Bestimmungen wurden doppelt durchgeführt. Dieselben Serumproben wurden gleichzeitig in sorgsam verschlossenen Röhrchen (Verdunstungsgefahr; Plastikstöpsel) bei genau $58^{\circ} 60$ Minuten im Wasserbad inkubiert, dann auf Zimmertemperatur abgekühlt und die GOT-Aktivität nochmals bestimmt. Die Enzymaktivität im nicht inkubierten Serum wird gleich $100 \%$ gesetzt und die nach Inkubation gemessenen Werte in Prozenten dieses Ausgangswertes berechnet. Es wurden 30 Sera klinisch Gesunder und 73 Sera von Patienten mit einwandfrei gesicherter Hepatitis epidemica in verschiedenen Phasen sowie 14 Sera anderer Kranker untersucht.

\section{Ergebnisse}

Sera mit normaler GOT-Aktivität, d. h. bis zu 40 Karmen-Einheiten, scheinen nur sehr gering thermolabil zu sein und weisen ein regelmäßiges Absinken von weniger als $10 \pm 3 \%$ des Ausgangswertes auf, gleichgültig, ob es sich um Gesunde oder Patienten nach klinisch gebesserter Hepatitis handelte. Fälle, bei denen keine Verringerung der GOT-Aktivität zu verzeichnen war, sind nur vereinzelt und ausnahmslos im Normalbereich der methodischen Streuung von $\pm 5 \%$. Interessant war das Verhalten der Serumproben dreier Kranker mit Carcinom, bei denen es nach Erhitzung zu keiner Änderung oder sogar zu einem leichten Anstieg der GOT-Aktivität kam. Leider war es uns nicht möglich, diese Beobachtung mit weiteren Fällen statistisch zu sichern.

Bei sämtlichen Sera mit hoher Ausgangsaktivität sank die GOT-Aktivität deutlicher. Es wurden ausschließlich Fälle mit Leberparenchymschädigung untersucht, 73 Patienten mit Hepatitis und 7 mit toxischen Leberschäden nach tuberkulostatischer Behandlung. Der Mittelwert betrug $47 \%$, die Streuung war beträchtlicher 
$( \pm 11)$. Es ist uns nicht gelungen, eine Gesetzmäßigkeit dieser Streuung, in Beziehung zu den Flokulationstesten und dem klinischen Bild der Erkrankung nachzuweisen.

\section{Diskussion}

Im Gegensatz zu der Lactatdehydrogenase ist die GOT im Serum Gesunder weitgehend thermostabil. Untersuchungen über die Thermolabilität der Transaminasen in wäßrigen Gewebsextrakten aus Organhomogenaten sind Gegenstand einer weiteren Mitteilung. Bei erhöhter Transaminasenaktivität im Serum, wie dies bei Leberparenchymschäden am deutlichsten zu beobachten ist, ist ein Teil der GOT thermolabil. Dies äußert sich in einer regelmäßigen statistisch gesicherten und reproduzierbaren Verringerung der Gesamtaktivität nach Inkubation bei $58^{\circ}$ auf die empirisch gewählte Dauer von 60 Minuten. Die Frage, ob es dabei um einen allgemeinen Denaturierungsprozeß des Enzymproteins oder um die selektive Inaktivierung eines wärmeempfindlicheren Isoenzyms der GOT geht, bleibt offen. Es ist nicht ausgeschlossen, $\mathrm{da} ß$ im Serum Hepatitiskranker thermolabile Aktivatoren der GOT zugegen sind. Die große Streuung dieser Ergebnisse sowie das Fehlen einer Korrelation zwischen Thermolabilität und anderen Befunden bei der Hepatitis nötigt uns, diese wärmeempfindliche GOT-Fraktion genauer zu definieren.

\title{
Literatur
}

1. Kellen, J., Zschr. exper. Med. 18, 326 (1963). - 2. Fleisher, G. A., C. S. Potrer und K. G. Wakim, Proc. Soc. exp. Biol. Med. 103, 229 (1960). - 3. Latner, A. L. und A. W. Skillen, Proc. Ass. Clin. Biochem. 2, 100 (1963). - 4. Wüst, H., H. ScröN und G.
Berg, Klin. Wschr. 40, 1169 (1962). - 5. Bergmeyer, H. U., Methoden der enzymatischen Analyse, Verlag Chemie GmbH, Weinheim Bergstr. (1962).
Dr. J. Kellen

Bratislava, Svidnická 9, CSSR

\section{Thermolabile Isoenzyme der Glutamat-Oxalacetat-Transaminase bei Hepatitis}

\author{
II. Mitteilung \\ Von Z. ZÁzVORKA \\ Technische Mitarbeit J. Kamarýt und VL. KarffK \\ Aus dem Zentrallaboratorium des Kreiskrankenhauses Most, Tschechoslowakei (Vorstand: Dr. med. Z. Zázvorka) \\ (Eingegangen am 16. August 1965)

\begin{abstract}
Die Thermolabilität des anodischen und kathodischen Isoenzyms der Glutamat-Oxalacetat-Transaminase im Serum bei Hepatitis epidemica wurde mit Hilfe der Agarelektrophorese untersucht. Die kathodische GOT-Fraktion zeigte sich deutlich thermolabiler. Dies ist durch Wärmeinaktivierung des teilweise abgebauten Enzymproteins zu erklären. Bei Transaminasen aus Gewebshomogenaten wurde in keiner Fraktion Thermolabilität gefunden. Umgekehrte Verhältnisse wurden bei dem Carcinomkranken mit Lebermetastasen gefunden.

The thermolability of anodic and cathodic isoenzymes of glutamate-oxaloacetate transaminase in the serum during Hepatitis epidemica was studied with the aid of agar electrophoresis. The cathodic GOT fraction was markedly more thermolabile. This can be explained by the heat inactivation of the partly degraded enzyme protein. No thermolabile fraction was found in the transaminases from tissue homogenates. The relationship was reversed in carcinoma patients with liver metastases.
\end{abstract}

Bei der Bestimmung der Gesamtaktivität der GlutamatOxalacetat-Transaminase ("GOT") im Serum ist bei erhöhten GOT-Werten ein deutlicher Aktivitätśverlust infolge von Erhitzung auf $58^{\circ} \mathrm{zu}$ verzeichnen. In dieser Mitteilung wird der Versuch unternommen, die Frage zu klären, ob diese Erscheinung die Folge einer Hitzedenaturierung des ganzen Enzymproteins oder der spezifischen Inaktivierung eines thermolabilen Isoenzyms der GOT ist.

$\mathrm{Da}$ es mit Hilfe der Agar-Elektrophorese reproduzierbar möglich ist, die GOT in zwei Fraktionen $(1-5,8$,
11-15), d. i. eine kathodische und eine anodische, aufzuteilen, stellten wir uns die Frage, welche dieser beiden Fraktionen diejenige ist, die unter Temperatureinfluß absinkt.

\section{Methodik}

Die Serum-GOT wurde auf 1-proz. Agargel auf $76 \times 26 \mathrm{~mm}$ Objektträgern elektrophoretisch aufgeteilt. Versuchsbedingungen: Veronalnatrium-Puffer $\mathrm{pH}=8,2$, Ionenstärke 0,05; Stromintensität 5-6 mA je Platte, 